\title{
Training military medics with animal models
}

Since 2009, the US Army has required specific combat trauma training for personnel with medical specialties prior to deployment. This training is a week-long review of basic skills needed to provide lifesaving interventions on the battlefield. The course consists of didactic lectures, video demonstrations and practice of procedures on partial task trainers (simulators) and mannequins. The week culminates in an exercise in which an anesthetized goat is used as a wounded patient. For many deploying medics, this is their first, and sometimes only, opportunity to work on a living, breathing and bleeding patient.

A few months ago, the Foundation for Biomedical Research posted an excerpt from a BBC article (Kelly, J. Who, What, Why: Does shooting goats save soldiers' lives? BBC News Magazine; 7 March 2013; http://www.bbc.co.uk/news/ magazine-21620521) about animals used in military training to its subscription newsletter known as Total e-Clips (http:// www.icontact-archive.com/172Rtdu1Q5 ykuE4whsOmhjtUs3Ng2uUk?w=4). The excerpt read, "The Department of Defense says such exercises 'prepare medics for the time-critical wounds they will encounter on today's battlefield.' However, animal rights groups say the training is 'barbaric' and unnecessary."

This snippet resonated strongly with me for several reasons. First, I lived in Maryland at the time (' $80 \mathrm{~s}$ ) when the US Department of Defense re-considered its continued use of dogs and pigs in military doctor training at the Uniformed Services University of the Health Sciences (Bethesda, MD). Second, my son-and I say this with fatherly prideis a $68 \mathrm{~W}$, an army medic. Nate is currently stationed in Afghanistan, and he has shared with me how his training and courses with animals have taught him to treat injured soldiers. And third, I have myself been addressing animal welfare and training for over 30 years.

After reading FBR's post, I immediately sent an email to Nate, asking what he thought about it. Following is his response:

"I have participated in over 10 goat labs (combat trauma training labs) as a student and an instructor. My first goat lab was when I was a private, and the only training I had had was what I learned in my Advanced Individual Training (AIT) at Fort Sam Houston. The live tissue training that I received before deployment to Iraq was invaluable. I felt so much more prepared to deploy and be ready for the types of injuries that we would see. After deployment, we did continual training to make sure our skills were sharp and that we could sustain life, whether it be human or animal. At this point, I changed roles and became an instructor, and I educated my squad of medics to be better prepared for the deployment to Afghanistan. I have spoken to all of my guys, and they agree that this training is the best that they have had. Being able to actually have hands-on experience makes the medic so much more competent and capable in the field of fire, so that there is not that horrible pause where someone's life is on the line. During the labs, there is always a veterinarian present with a large team of vet techs making sure that the goat is stable, properly anesthetized, and that no inhumane acts occur."

Let me share that rarely has my son written with such clarity. I was impressed with both his words and his passion. We can all read and appreciate his deep conviction for the animals, for people and for training.

We know it's not easy. I can't imagine the anxiety and adrenaline levels while in the battlefield for both human and animal medics. This is why training is so important. All students need actual handson preparation before the real thing, regardless of discipline.

While teaching and speaking about outreach for animal research, I often mention my son. I want my audience to hear as many aspects of the use of animals as possible, and I like to distribute the AALAS poster "Use of Animals in Biomedical Research" (http://www.aalas.org/bookstore/detail. aspx?id=191). I believe that we all come to understand better the importance of training when we know more about its impacts.

While working in Maryland, I met many $91 \mathrm{Ts}$ - the old term for military vet techs, now called 68Ts. They used animals in research and in training, while also serving as soldiers. Never did I meet one who was not passionate about animals, just like everyone else I know in laboratory animal science.

One more thing, on a very fatherly and personal level. My son shared this statement in his email response to me: "On a side note, all of the vets and a lot of the vet techs have seemed to know you in some way or the other." That makes us a big family in the community of animal use, training and welfare.

It seems the fruit does not fall far from the tree. I am proud of my son for serving in the military. I am proud that he also has an appreciation for those animals used in military training. And I am proud that he uses the word training as much as I do. 